\title{
ESTUDO DAS PROPRIEDADES DO CONCRETO PRODUZIDO COM POLIETILENO TEREFTALATO (PET) COM USO DE ADITIVO SUPERPLASTIFICANTE
}

Guilherme Noboru Sassaki Fidelis'; Tiago Souza Lopes; Daniele Araujo Altran'; Filipe Bittencourt Figueiredo²; Cassio Fabian Sarquis de Campos ${ }^{1}$

${ }^{1}$ Universidade do Oeste Paulista - Unoeste, Faculdade de Engenharia, Presidente Prudente, SP.

${ }^{2}$ Universidade Federal da Grande Dourados - UFGD, Faculdade de Engenharia, Dourados, MT. E-mail: noborumg3@gmail.com.

\section{RESUMO}

O setor industrial que atua na fabricação de produtos a partir de PET (Polietileno Tereftalato) tem gerado um volume crescente de resíduos sólidos, muitas vezes sem descarte adequado. Este estudo analisou a utilização de PET como agregado miúdo na produção de concreto, nas proporções de $5 \%, 10 \%, 15 \%, 20 \%$ e $25 \%$, com aditivo superplastificante redutor de água. 0 trabalho teve como objetivo analisar a viabilidade através da resistência à compressão. Obteve-se o valor de 12,95 $\mathrm{MPa}$ para o traço com 5\% de substituição aos 28 dias de idade. 0 traço apresentado nesse estudo pode ser utilizado para fins não estruturais, como calçadas, bancos de concreto e regularização de piso.

Palavras-chave: Concreto; PET; Aditivo Superplastificante; Agregado Reciclado; Resíduos Sólidos.

\section{STUDY OF THE PHYSICAL PROPERTIES OF CONCRETE PRODUCED WITH POLYETHYLENE TEREPHTALATE (PET) WITH THE USE OF SUPERPLASTICIZER ADDITIVE}

\begin{abstract}
The industrial sector that deals with products made up by PET (Polyethylene Terephthalate) has generated an increasing volume of solid waste, often without adequate disposal. This study analyzed the use of PET as a small aggregate in the production of concrete in the proportion of $5 \%$, $10 \%, 15 \%, 20 \%$ and $25 \%$, with water reducing superplasticizer additive. The objective of this work was to analyze the feasibility through the resistance to compression. The value of $12.95 \mathrm{MPa}$ for the trait with $5 \%$ substitution at 28 days of age was obtained. The trait presented in this study can be used for non-structural purposes, such as sidewalks, concrete benches and floor regularization. Keywords: Concrete; PET; Superplasticizer additive; Recycled aggregate; Solid waste.
\end{abstract}




\section{INTRODUÇÃO}

A construção civil representa um dos setores de maior importância na economia brasileira, sendo responsável por $5,6 \%$ do PIB (Produto Interno Bruto) do país (IBGE, 2016). A significativa atividade da construção tem também um impacto na produção de resíduos sólidos, sendo um setor com alta contribuição através de desperdícios e demolições em construções (PINTO, 1999).

Em 2015, a indústria de PET no Brasil foi responsável pela produção de aproximadamente 537 mil toneladas do material. Desse montante, o volume reciclado no ano foi de $51 \%$ (ABIPET, 2016).

Por outro lado, o crescimento no uso do concreto faz com que recursos naturais sejam extraídos excessivamente para serem utilizados como agregado. Como exemplo a areia, que é o agregado miúdo natural mais utilizado na produção de concreto (CABRAL et al, 2010).

Visando a reutilização de resíduos sólidos, pesquisas têm buscado o aprimoramento do concreto produzido com materiais reciclados, sendo sugeridos traços que utilizam ambos agregados naturais e reciclados (TAM; GAO; TAM, 2005). Entre as diversas propriedades físicas analisadas, notáveis variações têm sido observadas, principalmente nos valores de massa específica, absorção de água, resistência à compressão e trabalhabilidade (RODRIGUES; FUCALE, 2014). Sendo os dois últimos fatores de grande importância para o concreto a ser utilizado em obras, principalmente em elementos estruturais, como vigas e pilares. A causa de tais variações pode estar no fato de que o concreto produzido com o uso de agregado reciclado apresenta falta de hidratação e baixa fluidez. Como consequência, o traço produz um concreto de baixa trabalhabilidade, que pode ser observada nos baixos valores de slump test (CAMPOS et al.,2014).

Por outro lado, um dos componentes que apresentam resistência à segregação é o aditivo plastificante ou superplastificante, que garante também alta fluidez ao concreto (PEREIRA, 2016).

Uma vez utilizados com a função de conferir uma plastificação ao concreto, sem necessidade de modificação na relação água/cimento $(\mathrm{a} / \mathrm{c})$, os aditivos superplastificantes diminuem significantemente as segregações dentro do concreto. Tal efeito melhora a trabalhabilidade do concreto, permitindo um melhor adensamento (MARTINS, 2005).

Campos (2014) indicou redução da resistência à compressão ao apresentar valores de 12,66 MPa com uma substituição de apenas 5\% de agregado natural por PET reciclado, comparando a 29,22 MPa no traço piloto sem uso do agregado reciclado.

Esse trabalho teve como objetivo a utilização de traços de concreto produzido com agregado reciclado em substituição à areia, sendo estudados traços com diferentes proporções de substituição e baseados em um traço piloto. Sem a substituição de agregado, o traço apresenta resistência à compressão de $20 \mathrm{MPa}$, sendo um valor amplamente adotado como sendo uma resistência mínima para utilização em obras convencionais.

\section{METODOLOGIA}

Esse trabalho tem como metodologia científica o método experimental, caracterizado pelo procedimento de submeter o objeto de estudo à diversas variáveis, analisando a resposta do mesmo dentro de um cenário conhecido (PRODANOV, 2013). Esse método permite conhecer a influência de determinada variável no objeto sendo analisado, nesse caso trata-se das alterações nas propriedades do concreto causadas pela substituição de agregado natural por PET.

Para esse estudo, foram produzidos traços de concreto com diferentes proporções de agregado reciclado, alterando gradualmente de $5 \%$ em $5 \%$ o percentual de substituição de agregado natural pelo agregado de PET. Dessa maneira, o trabalho teve como objeto de estudo os traços com proporção de 5\%, 10\%, 15\%, 20\% e 25\% de substituição de agregado miúdo. Foi produzido um concreto com traço piloto que foi utilizado como referência, sem alteração na quantidade de agregado. Os resultados de todos os traços com substituição de agregado foram 
comparados com os resultados do traço piloto. O concreto foi produzido com a utilização de cimento Portland CPII-E 32, areia, brita 1, agregado reciclado de PET e aditivo superplastificante redutor de água. Após sua fabricação, o mesmo foi submetido ao ensaio de trabalhabilidade, que é realizado através do slump test, executado de acordo com a norma ABNT NBR NM 67:1998. Foram produzidos corpos de prova com o concreto obtido e realizados ensaios de resistência à compressão quando estes atingiram idades de 7, 14 e 28 dias, em conformidade com a norma ABNT NBR 5739:2007.0 agregado de PET reciclado apresenta granulometria equivalente à areia média, conforme observado após ensaio de determinação de composição granulométrica. $O$ agregado reciclado tem como origem garrafas PET que passam por processo de lavagem e trituração.

\section{RESULTADOS}

A Tabela 1 apresenta uma diminuição do abatimento do cone em função do aumento de substituição do agregado.

Tabela 1.Resultados do Slump Test (cm).

\begin{tabular}{|c|c|}
\cline { 2 - 2 } \multicolumn{1}{c|}{} & NBR NM 67:1998 \\
\hline Traço & Abatimento do Cone $\mathbf{( c m )}$ \\
\hline Piloto & 6,5 \\
\hline $5 \%$ de PET & 11,5 \\
\hline $10 \%$ de PET & 9,5 \\
\hline 15\% de PET & 1,0 \\
\hline 20\% de PET & 0,0 \\
\hline 25\% de PET & 0,0 \\
\hline
\end{tabular}

Calculou-se a média de 3 resultados para a composição dos valores de resistência. Na Tabela 2 apresenta-se as médias de resistência à compressão obtidas.

Tabela 2.Média da resistência à compressão (MPa).

\begin{tabular}{|c|c|c|c|}
\cline { 2 - 4 } \multicolumn{1}{c|}{} & \multicolumn{3}{c|}{ Idade do Concreto } \\
\hline Traço & 7 Dias & 14 Dias & 28 Dias \\
\hline Piloto & 12,67 & 14,14 & 18,77 \\
\hline $5 \%$ de PET & 8,87 & 10,62 & 12,95 \\
\hline $10 \%$ de PET & 9,61 & 10,52 & 10,34 \\
\hline $15 \%$ de PET & 7,24 & 9,31 & 9,23 \\
\hline $20 \%$ de PET & 7,26 & 7,49 & 7,68 \\
\hline $25 \%$ de PET & 3,86 & 4,17 & 5,01 \\
\hline
\end{tabular}

Fonte: Os Autores.

Segue a representação gráfica dos resultados obtidos nas Figuras 1 e 2 . Os valores apresentados estão em MPa. 
Figura 1. Resistência à compressão (Piloto, 5\% e 10\% de substituição).

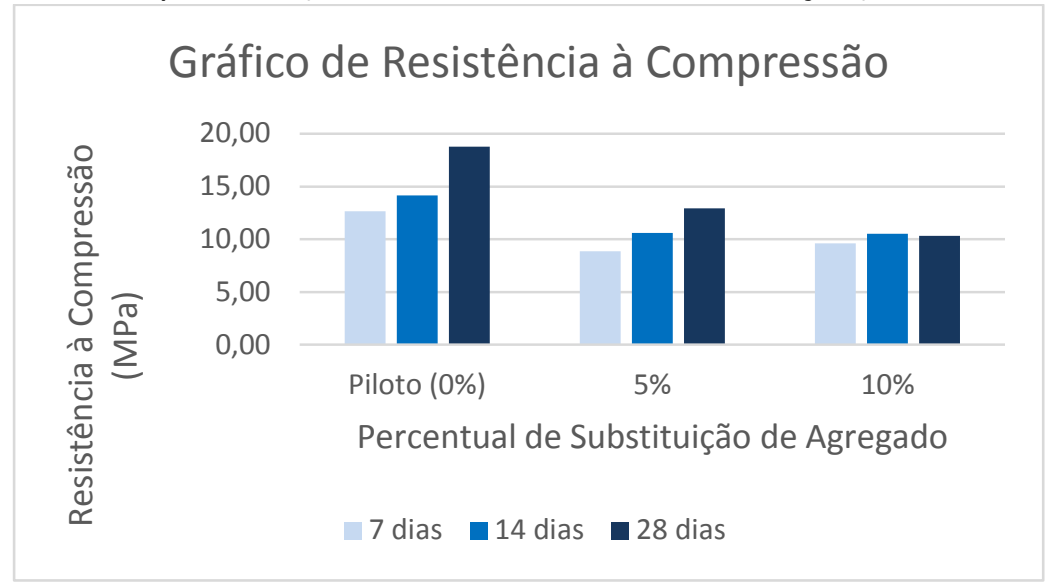

Fonte: Os autores.

Figura2. Resistência à compressão (15\%, 20\% e 25\% de substituição).

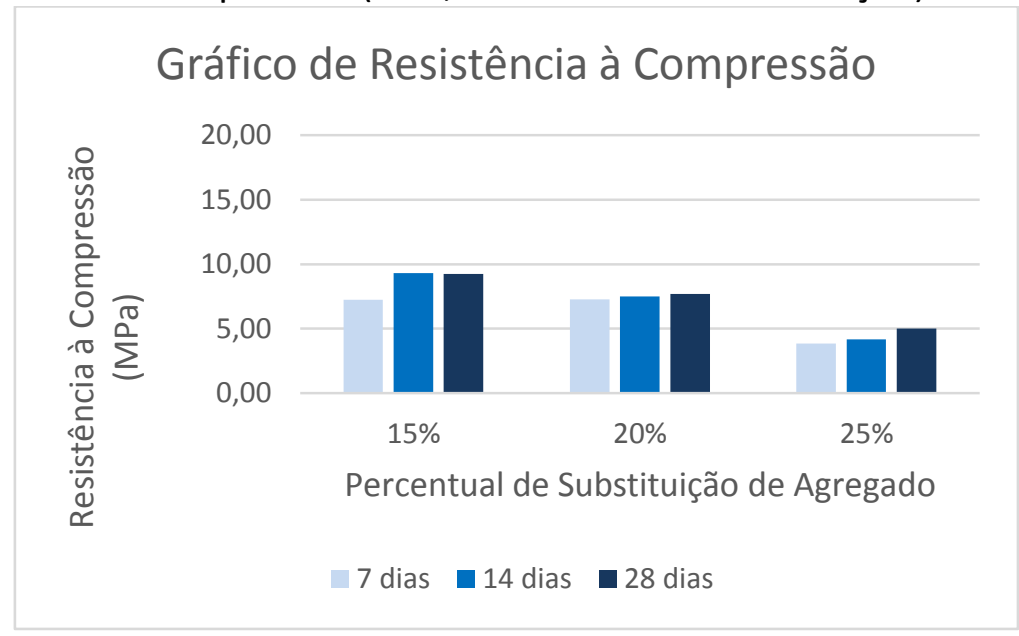

\section{DISCUSSÃO}

A utilização do aditivo superplastificante redutor de água nos traços utilizados teve como objetivo conferir uma trabalhabilidade adequada ao concreto, como forma de mitigar a retenção de água nas partículas do agregado reciclado de PET. No entanto, um resultado muito alto indica um concreto com fluidez excessiva, que se reflete em uma baixa resistência à compressão. Os traços com valores adequados de slump test foram: traço piloto, $5 \%$ de PET e $10 \%$ de PET. Nota-se que os traços de $15 \%, 20 \%$ e $25 \%$ apresentaram valores baixos, com abatimento do cone igual ou menor que $1 \mathrm{~cm}$. Essa baixa trabalhabilidade dos últimos 3 traços se refletiu nos resultados de resistência à compressão (Figura 2). Á medida que se aumenta o percentual de substituição, ocorre uma queda da resistência à compressão.

Os resultados indicam que a inserção do agregado reciclado de PET no traço causa grande influência na resistência do concreto. Como pode ser notado no traço com $5 \%$ de substituição, uma pequena proporção de agregado reciclado causou uma considerável diminuição na resistência à compressão do corpo de prova.

Nota-se que os traços com substituições de $10 \%, 15 \%$ e $20 \%$ de agregado mantiveram sua resistência à compressão após 14 dias de sua moldagem, visto que os resultados com 28 dias de idade apresentaram pouca variação. Em contraste, os traços com 5\% 25\% de PET apresentaram ganho de resistência à compressão até os 28 dias de idade. 


\section{CONCLUSÃO}

A utilização de agregado reciclado de PET na produção de concreto proporciona uma alternativa no aproveitamento do material reciclado, ainda que em pequenas proporções. No entanto, nesse estudo comparativo com o concreto convencional, representado pelo traço piloto, observa-se a significante diferença de resistência à compressão do traço com substituição de agregado miúdo. No presente trabalho, a utilização de aditivo superplastificante aumentou a trabalhabilidade dos traços com substituição de agregado, conforme constatado nos resultados de slump test. No entanto, a utilização de percentuais superiores a $20 \%$ de agregado reciclado permanece incerta devido ao valor extremamente baixo de abatimento do cone.

Conforme notado por Campos et al. (2014) o concreto produzido com agregado reciclado de PET apresenta baixa trabalhabilidade, ocasionando um maior índice de vazios nos corpos de prova. Como pode ser observada nesse trabalho, a baixa trabalhabilidade do concreto influencia diretamente na sua resistência à compressão, sendo esta a propriedade de maior relevância para a construção civil.

Com a utilização de aditivo superplastificante redutor de água, sem alteração no fator a/c, obteve-se um concreto produzido com PET com melhor trabalhabilidade e resistência à compressão superior ao maior valor encontrado por Campos et al. (2014). O maior valor obtido neste estudo foi de 12,95 MPa para o traço com $5 \%$ de substituição aos 28 dias de idade com slump test de $11,5 \mathrm{~cm}$. Campos (2014) apontou resultado de 12,66 MPa para o mesmo traço e resultado de abatimento do cone de $2,0 \mathrm{~cm}$. Portanto, o aumento de resistência à compressão se deu através da utilização de aditivo superplastificante, assim como maior trabalhabilidade do concreto em estado fresco. O concreto produzido com uso de PET apresentou resistência abaixo do mínimo exigido para fins estruturais, porém pode ser empregado para fins não estruturais, entre eles pode-se citar a produção de calçadas, bancos de concreto e regularização de piso. Através da utilização do traço apresentado nesse estudo é possível reduzir a utilização da areia, que é um recurso natural finito assim como proporcionar uma destinação correta para as centenas de milhares de toneladas de PET que são descartadas anualmente.

\section{REFERÊNCIAS}

ASSOCIAÇÃO BRASILEIRA DA INDÚSTRIA DOPET - ABIPET. Disponível em: www.abipet.org.br. Acesso: 8 de abril de 2017.

ASSOCIAÇÃO BRASILEIRA DA INDÚSTRIA DOPET - ABIPET. 9o Censo da Reciclagem de PET no Brasil. 2013. Disponível em:<www.abipet.org.br>. Acesso: 17 de julho de 2016.

ASSOCIAÇÃO BRASILEIRA DE NORMAS TÉCNICAS - ABNT. NBR NM 67 - Determinação da consistência pelo abatimento do tronco de cone. Rio de Janeiro, 1998.

ASSOCIAÇÃO BRASILEIRA DE NORMAS TÉCNICAS - ABNT. NBR 5739 - concreto: ensaio de compressão de corpos-de-prova cilíndricos. Rio de Janeiro, 2007.

CABRAL, A. E. B.; et al. Mechanical properties modeling of recycled aggregate concrete. Construction and Building Materials, vol.24, n.1, pp.421-430, Out 2010.

CAMPOS, C. F. S. et al. Estudo das Propriedades Físicas do Concreto Produzido com Polietileno Tereftalato. ColloquiumExactarum, Presidente Prudente: Unoeste, v.6, n.4, p.31-39, Nov-Dez 2014.

INSTITUTO BRASILEIRO DE GEOGRAFIA E ESTATÍSTICA. Contas Nacionais Trimestrais: indicadores de volume $\quad$ velores correntes. Disponível em: 
$\mathrm{ftp}$ //ftp.ibge.gov.br/Contas_Nacionais/Contas_Nacionais_Trimestrais/Fasciculo_Indicadores_IBGE/pib -vol-val_201604caderno.pdf. Acesso em: 8 maio 2017.

MARTINS, V. da C. Otimização dos processos de dosagem e proporcionamento do concreto dosado em central com a utilização de aditivos: estudo de caso. 198p. Dissertação (Mestrado). Programa de PósGraduação em Engenharia Civil - Universidade Federal de Santa Catarina. Florianópolis, 2005.

PEREIRA, J. R. Análise da produção de concreto auto adensável (CAA) e da adição do Pó de Poli Tereftalato de Etileno (PET) Reciclado. 107p. Dissertação (Mestrado). Universidade Estadual de Campinas, Faculdade de Tecnologia. Limeira, 2016.

PINTO, T. de P. Metodologia para a gestão diferenciada de resíduos sólidos da construção urbana. 218p. Tese (Doutorado). Escola Politécnica da Universidade de São Paulo. Departamento de Engenharia de Construção Civil. São Paulo, 1999.

PRODANOV, C. C. Metodologia do trabalho científico: métodos e técnicas da pesquisa e do trabalho acadêmico. $\quad 2^{a}$ ed. Novo Hamburgo: Feevale, 2013. Disponível em: <http://www.feevale.br/Comum/midias/8807f05a-14d0-4d5b-b1ad-1538f3aef538/Ebook\%20Metodologia\%20do\%20Trabalho\%20Cientifico.pdf>. Acesso em 10 maio 2017.

RODRIGUES, C. R. S.; FUCALE, S. Dosagem de concretos produzidos com agregado miúdo reciclado de resíduo da construção civil. Ambiente construído, vol.14, n.1, pp. 99-111, jan. 2014.

TAM, V.W.Y.; GAO, X.F.; TAM, C.M. Microstructural analysis of recycled aggregate concrete produced from two-stage mixing approach, Cement and Concrete Research,v. 35, n. 1, pp. 1195-1203, Mai 2005, https://doi.org/10.1016/i.cemconres.2004.10.025. 